\title{
THE RELATIONSHIP BETWEEN LESION LOCALIZATION AND SWALLOWING DISORDERS
}

\author{
Mirna Zelić1, Jelena Todorović2, Dragan Pavlović3 ${ }^{3}$ Lana Jerkić3,4
}

\begin{abstract}
Swallowing disorders (dysphagia) include difficulty in swallowing and controlling saliva, as well as feeding difficulties. These disorders affect all age groups from newborns to the elderly and can be the result of congenital abnormalities, damage of anatomical structures that affect swallowing, as well as various medical conditions. Dysphagia may be acute (eg. stroke) or may progress over time (eg. tumors and progressive neurological diseases). Numerous regions participate in the act of swallowing and they include precentral gyrus, postcentral gyrus, premotor zone, the supplementary motor area, operculum, insula, precuneus, prefrontal cortex, temporal lobe, cerebellum, brainstem, the frontal lobe, association areas, thalamus, and basal ganglia. It is extremely important to understand the swallowing process in order to further give an adequate approach in the treatment of disorders of this function.

Acta Medica Medianae 2021;60(1):85-91.
\end{abstract}

Key words: dysphagia, swallowing disorders, brain lesions, pathophysiology of swallowing, treatment of dysphagia

\footnotetext{
${ }^{1}$ Institute for Psychophysiological Disorders and Speech Pathology "Prof. dr Cvetko Brajović", Belgrade, Serbia ${ }^{2}$ Health Center Zvečan, Zvečan, Serbia

${ }^{3}$ Faculty of Special Education and rehabilitation, Belgrade, Serbia

${ }^{4}$ Scholarship holder of Ministry of Education, Science and

Technological Development of Republic of Serbia
}

Contact: Mirna Zelić

52 Kralja Milutina St., 11000 Belgrade, Serbia

E-mail: mirnabzelic@gmail.com

\section{Introduction}

Swallowing disorders (dysphagia) include difficulty in swallowing and controlling saliva, as well as feeding difficulties. In the broadest sense, dysphagia encompasses all behavioral, sensory, and preliminary motor actions in preparation for swallowing, including awareness of the upcoming feeding situation, visual recognition of food, and increased production of saliva as a physiological response to food (1). Dysphagia affects all age groups from newborns to the elderly and can be a consequence of congenital abnormalities, damage of anatomical structures that affect swallowing, as well as various medical conditions. Neurological disorders that affect the occurrence of swallowing disorders can be cate- gorized by anatomic location of the lesion in the central nervous system (CNS) and peripheral nervous system (PNS). CNS disorders can be degenerative and neurodegenerative, while as a rule, PNS disorders are degenerative. Degenerative disorders can be progressive and relapsing-remitting (2).

This paper aims to make a correlation between swallowing and the localization of the lesion that affects the physiology of swallowing. The lack of a more precise study of the association between brain lesion localization and swallowing physiology derives from the limitations of neuroimaging methods as well as quantitative swallowing evaluations. Research has been largely limited to broader areas such as infratentorial, supratentorial, cortical, subcortical, and bulbar (3).

\section{Dysphagia in neurological diseases}

Dysphagia is a common deficit after a stroke and is associated with pneumonia, malnutrition, dehydration, but also with a decline in quality of life. Swallowing disorders are found in 55 to $88 \%$ of stroke survivors. Researches of the connections between the location of the brain lesion and the physiological aspects of swallowing showed different and overlapping localizations of lesions mainly in the right hemisphere, including cortical regions, subcortical regions, and white matter (4). There are many studies that link swallowing disorders to acute ischemic stroke and that have found an association between parietal-temporal or medullary lesions and damage to laryngeal elevation (5) and they are followed by insular lesions and delayed pharyngeal 
reflex triggering (6) and nonspecific subcortical regions and slow bolus transit.

Traumatic brain injuries that result in swallowing disorders depend on the location of the injury and are more often diffuse in relation to stroke-related lesions. Cognitive disorders are also emphasized in traumatic brain injuries and there are studies that indicate an association between cognitive deficits and swallowing disorders (5). In brain tumors, swallowing disorders are common if there is an infiltration of the tumor in an area important for the act of swallowing.

Patients with dementia exhibit numerous swallowing and eating disorders. The most common form of dementia is Alzheimer's disease. These patients develop food agnosia, and as the disease progresses, apraxia for feeding and swallowing develops. Swallowing apraxia makes it difficult to initiate the oral phase of swallowing. Oral tactile food agnosia is also reported. Patients with dementia often keep food in their mouths without swallowing it (8).

Parkinson's disease is the most common form of movement disorder and these patients can develop disorders in each of the phases of swallowing. The most common disorders are in the oral phase and can be the initial symptoms of the disease. The limited range of motion of the mandible increases the time of food preparation in the oral phase (9).

Repetitive tongue movement back and forth is specific for Parkinson's disease with the inability of the bolus to leave the oral cavity as well as the inability to control saliva. In Parkinson's disease, there is also a decrease in the frequency of spontaneous swallowing, xerostomia, delay in triggering the pharyngeal reflex, cough. Laryngeal closure may be incomplete during the pharyngeal swallowing phase. These symptoms increase the risk of food aspiration. In the terminal stages of the disease, dementia, as well as impulsive behavior during feeding, further complicate swallowing that is already difficult (9).

Amyotrophic lateral sclerosis (ALS) is also a progressive neurological disease. In ALS, swallowing disorders begin with a reduction in tongue movement, inability to lateralize food, lips occlusion weakening, as well as velar weakening. The act of swallowing disorder continues with the delay of the trigger of the swallowing reflex and the weakened movements of the base of the tongue (10).

Patients with multiple sclerosis (MS) may have swallowing disorders that correlate with any neurological lesion, from the cerebral cortex, through the brainstem to the cranial nerves. Precisely because the damage can affect one or more cranial nerves, patients with MS can have different degrees of swallowing disorders. Delay in triggering the pharyngeal swallowing reflex as well as reduction of tongue movement and pharyngeal constrictor are most commonly described swallowing disorders in MS (11).

\section{Physiology of swallowing}

Eating and swallowing are complex motor actions and they include voluntary and reflex activities of 30 muscles and five cranial nerves and have two biological roles:

1) food transfer from the oral cavity to the stomach and

2) respiratory organs protection.

Different authors point to different divisions of swallowing phases. According to Logeman (8), swallowing has four phases:

a) oral preparatory phase,

b) oral transit phase,

c) pharyngeal and

d) esophageal phase. Matsuo and Palmer (12) additionally divide the oral transit phase into three more levels:

- food transfer through the oral cavity, food processing by chewing and saliva, and

- food transfer to the oropharynx.

A rough division into only three phases can be found in the literature: oral, pharyngeal and esophageal.

Eating, swallowing and breathing are closely related. In healthy adults, breathing is interrupted during swallowing due to both physical closure of the airways by lifting of the soft palate and closure of the epiglottis and neural control of respiration in the brainstem. When sucking, the newborn swallows and breathes at the same time. Understanding the physiology and pathophysiology of eating and swallowing are key to the evaluation and treatment of swallowing disorders.

\section{Oral Preparatory phase}

The patterns of movement in the oral preparatory phase vary depending on the viscosity of the food, its quantity as well as the degree of pleasantness (subjective sense of taste). At the moment when the liquid is placed in the mouth, the lips close, which requires nasal breathing, and the posterior soft palate and tongue prevent premature leakage of fluid into the pharynx. In the case of solid food, the tongue rotates laterally by placing food on the teeth due to chewing. At this stage, the food bolus is softened by saliva.

\section{Oral transit phase}

During the oral transit phase, the tip of the tongue is raised, touches the alveolar ridge and the posterior part is lowered and opens the passage to the pharynx. The dorsal surface of the tongue moves upwards, expanding the area of contact with the palate and pressing the fluid against the palate. In the case of solid food, the oral transit phase has the role of completely preparing the food and facilitating the pharyngeal phase.

\section{Pharyngeal phase}

The pharyngeal phase starts with triggering the pharyngeal swallowing reflex. The velopharyngeal sphincter rises and closes the path to the oropharynx, the suprahyoid muscles push the larynx up and forward, and the epiglottis closes. Pushing the larynx forward and under the base of the tongue also causes the abduction of the vocal cords, which 
closes the glottis and thus prevents the penetration of food inside the larynx and further into the airways. These actions achieve the separation of the digestive and respiratory tract, filling the pharynx, its passive emptying and active peristalsis of the pharyngeal muscles.

\section{Esophageal phase}

The esophagus (esophagus) consists of striated and smooth muscles and its role is to transfer food to the stomach. With peristaltic movements, the food goes down. This is an involuntary phase of swallowing and is slower than the pharyngeal phase.

\section{Brain lesions and swallowing disorders}

Papers on swallowing disorders most often list unilateral and bilateral brainstem lesions, as well as cortical and subcortical lesions. In persons who had damage in the posterior regions, which do not have a motor component, no swallowing disorders were recorded, except in the case of edema that affected the anterior areas of the cortex. Numerous regions participate in the act of swallowing and include precentral gyrus, postcentral gyrus, premotor area, supplementary motor area, operculum, insula, precuneus, prefrontal area, temporal lobe, cerebellum, brainstem, frontal lobe, association areas, thalamus, and basal ganglia (4).

\section{The role of the cerebral cortex in the act of swallowing}

Swallowing begins as sensory information that moves from the pharynx to the spinal nerves to the brainstem and thalamus, which then sends information to specific areas of the somatosensory areas of the parietal lobe where the sensations of a bolus (bite) in the oropharynx are registered. Studies examined on the activity of the cerebral cortex in the act of swallowing report the activity of the postcentral gyrus (gyrus postcentralis) in both voluntary and automatic swallowing (13). This area is responsible for processing the oropharyngeal stimulation created by the movements of the tongue, lower jaw, palate and pharyngeal musculature. Activations of the supplementary motor zone and the premotor zone in voluntary swallowing are also mentioned, and parallel processes of swallowing and movement of the tongue in the supplementary motor zone and postcentral gyrus are indicated. The supplemental motor zone activated for premotor aspects of swallowing and receiving subcortical input from the basal ganglia activates the precentral gyrus.

\section{disorders \\ Cerebral cortex lesions and swallowing}

Patients with lesions in the left or right hemisphere of the cerebral cortex show various disorders of the swallowing function. Damage to the left hemisphere may be accompanied by mild to severe swallowing apraxia, which is mainly associated with oral apraxia. Swallowing apraxia is charac- terized by a delay in the initiation of the oral phase of swallowing with the absence of tongue movement, which is expected in response to the presence of food in the mouth. These patients eat and drink more easily without verbal orders to do so even if it is a spontaneous action. In the mentioned lesions, there is a slight delay in the oral phase (3 to 5 seconds) and a delay in the triggering of the pharyngeal swallowing reflex (2 to 3 seconds) (4). Recent studies have indicated that disorders of the oral swallowing phase are mostly correlated with lesions in the frontal lobe and precentral gyrus of the left hemisphere (14). With damage in the right hemisphere of the cerebral cortex, there is a longer delay in triggering the pharyngeal swallowing reflex and a delay in the elevation of the larynx, so aspiration of food and drink is possible. Moon et al. (15) claim that lesions in the left frontal lobe are closely associated with a delay in the oral phase of swallowing and a disorder of practice.

\section{The role of the brainstem in the act of swallowing and disorders}

Sensory information from the pharynx is transmitted by the afferent fibers V, VII, IX and X of the cranial nerve and terminates in the nucleus tractus solitarius (the medulla oblongata) in the brainstem. Through afferent fibers, information reaches the cerebral cortex where the cortical response to swallowing begins (16).

Lesions in the lower brain stem (medulla oblongata) are accompanied by a significant disturbance of the oropharyngeal phase of swallowing due to the location of important swallowing centers n.tractus solitarii and $\mathrm{n}$. ambiguous. Most patients with a unilateral medullary lesion have an intacted oral bolus control (bite) but they do have significant trigger damage and neuromotor control of the pharyngeal swallowing phase. If the trigger of the pharyngeal swallowing reflex exists, it is generally delayed by as much as 10 to 15 seconds. When pharyngeal swallowing is triggered, the following is observed in these patients:

1) reduced laryngeal elevation, which leads to reduced opening of the cricopharyngeal region and collection of food residues in the pyriform sinuses;

2) unilateral weakness of the pharynx, which again leads to the collection of food residues in the pyriform sinuses. Unilateral paresis or paralysis of the vocal cords has been observed in a certain number of patients (17).

Also, in a certain percentage of patients, swallowing function will not recover to even four to six months after a stroke in the medulla oblongata caused by a stroke. In most cases, it is not possible to take food orally in the first two weeks after the stroke, while after the third week, the swallowing function gradually recovers only if there are no other factors that complicate recovery. In patients with a lesion in the brainstem, the possibility of cricopharyngeal myotomy remains, if there is spasticity of the cricopharyngeal muscle (m. Cricopharyngeus) even after six months. Lesions in the middle part of the brainstem (pons) leave patients with severe pharyngeal hypertonia and delayed pharyngeal 
swallowing triggers or complete absence of pharyngeal swallowing, with unilateral spastic paresis or pharyngeal wall paralysis as well as reduction of clavicular pharyngeal elevation and laryngeal dysfunction. Recovery of patients with brainstem damage is lengthy and difficult. Dysphagia of this origin requires intensive therapy and care.

\section{The role of insula and operculum in the act of swallowing and their damage}

Martin et al. (17) stated that the operculum contributes to the temporal organization of swallowing, i.e. the control and coordination of chewing as well as the sensory function of the oral cavity and pharynx. Other authors (16) state that the insula plays an important role in the act of swallowing due to its connection with the primary and supplementary motor zone, thalamus and $n$. tractus solitarii which are important centers in the mediation of oropharyngeal swallowing.

According to Logeman (8), discrete lesions of the anterior part of the insula can result in swallowing disorders. One recent study indicates a significant delay in the pharyngeal swallowing phase (16).

\section{swallowing}

The role of the cerebellum in the act of

The cerebellum, together with the pons, participates in maintaining balance and controlling movement (19). The role of the cerebellum in the act of swallowing was studied in 24 studies (20) and it was concluded that the cerebellum has a functional (not anatomical) connection with the primary motor zone, basal ganglia and thalamus in the voluntary act of swallowing. Activated structures work as independent modules and each module has a special role in swallowing.

The cerebellum has a role in controlling the sequencing and coordination of movements of the orolingual and pharyngeal musculature. Malandraki et al. (21) investigated brain activation within the act of swallowing and came to the result that when swallowing fluid, certain anterior and posterior parts of the cerebellum are activated together with other cortical and subcortical structures. Grabski et al. (22) investigated the role of the cerebellum in supralaryngeal and laryngeal movement control and they concluded the positive role of the cerebellum in the coordination of oral motor movements in the act of swallowing.

\section{Subcortical lesions and swallowing disorders}

Subcortical lesions may involve sensory pathways to and from the cerebral cortex. Subcortical brain lesions are accompanied by:

- a slight delay (3 to 5 seconds) in the oral phase;

- delay (3 to 5 seconds) in the pharyngeal swallow trigger;

- mild to moderate impairment of neuromuscular control of pharyngeal swallowing.
There are studies that indicate a positive correlation between the extent of subcortical hemorrhage and the severity of swallowing disorders as well as the association of pharyngeal swallowing phase disorders and basal ganglia lesions in the right hemisphere and corona radiata (23). Aspiration was associated with lesions in the putamen of the right hemisphere (14). The research conducted by Im. I et al. (16) also showed that lesions in the caudate nucleus affect aspiration or airway dysfunction.

\section{Screening and diagnosis of swallowing disorders}

Screening for dysphagia includes early detection of signs and symptoms in patients who are at high risk of developing swallowing disorders. Screening procedures provide information on the presence of aspiration, inadequate swallowing, the presence of food debris in the mouth and pharynx, the presence of a hoarse voice, and coughing during or immediately after a meal. The purpose of screening is to determine the likelihood that swallowing disorder exists as well as the need for further assessment of swallowing (24).

There are indications for instrumental and non-instrumental screening methods. For patients with signs and symptoms of pharyngeal dysphagia, instrumental examination methods provide more objective findings.

Non-instrumental examination involves observing the patient's behavior in relation to swallowing function, whether signs and symptoms of swallowing disorders are present, taking into account fatigue during feeding, body posture and environment. This type of examination can provide enough data to the clinician to diagnose oral dysphagia. Non-instrumental assessment of swallowing includes insight into the history of the case (examination of medical records), examination of the oral cavity, assessment of cranial nerves which includes assessment of the structure of the face, jaw, lips, tongue, hard and soft palate, oral cavity and mucous membranes. Non-instrumental examination includes functional assessment of muscles used in swallowing, symmetry, tone, strength and range and coordination of movements, observation of head and neck movement control, assessment of overall physical, social and cognitive status and observation of feeding flow within which salivation and chewing are observed (24).

Instrumental techniques are used to evaluate oral, pharyngeal, laryngeal, and esophageal functions as well as to determine the appropriateness and efficacy of treatment strategies. Videofluoroscopy or modified ingestion of barium is a radiological procedure that provides insight into the oral, pharyngeal and esophageal function. The most comprehensive assessment of swallowing disorders and the recognized gold standard is modified barium ingestion. Fiberoptic endoscopic assessment of swallowing is a procedure that can be performed in the field but does not allow the visualization of the swallowing phases such as video fluoroscopy. 


\section{Treatment of swallowing disorders}

Regardless of the type of swallowing disorder, there are conditions that must be met in order to start treatment. Special attention is paid to the patient's posture, his vigilance, respiratory status and the oral cavity. When these conditions are met, i.e. when the patient is able to be in an upright position, if they are awake, without respiratory difficulties and if the denture is adequate, we can rely on: possible adaptations of the environment and food, specific exercises that will strengthen musculature involved in swallowing and provide protective mechanisms during the act of swallowing. The patient should sit upright, during the meal the environment must be free of noise and distractions. In case of difficulty grasping by hand, custom cutlery set can be used.

\section{Compensatory techniques}

Compensatory techniques control the course of feeding or drinking and eliminate symptoms, but they do not necessarily change the physiology of swallowing. These techniques are:

1) changes in body posture that potentially change the dimensions of the pharynx or direct food transfer without patient effort,

2) sensory input reduction,

3) modify food volume and intake rate,

4) change consistency and viscosity of food,

5) intraoral prosthetics (8) (25).

Changing body posture involves several techniques. The lowering of the chin towards the chest enables the narrowing of the pharynx by moving the tongue and epiglottis to the posterior position. The risk of food aspiration is reduced. By rotating the head to the weaker side, in case of unilateral paresis or paralysis of the larynx, a wider opening of the healthy side of the pharynx is provided. By rotating the head to the stronger side, we enable the bolus to follow the stronger wall of the pharynx (25).

Sometimes it is necessary to change the consistency of food, if chewing is difficult, the food softens. This reduces the risk of food suffocation. Food also adapts in cases of poor salivation, poor tongue mobility and loss of sensory function. The choice of contrasting temperatures and flavors can facilitate sensitivity in the oral cavity and pharynx and contribute to faster swallowing. If there is a delay in triggering the pharyngeal reflex, a change in viscosity will reduce the risk of direct aspirations. The longer the pharyngeal reflex delay the higher the viscosity must be.

\section{Therapeutic procedures}

Therapeutic procedures are designed to change the physiology of swallowing. They improve the range of motion of the oral and pharyngeal structures. These techniques improve a sensory input before the act of swallowing, teach the patient to voluntarily take over the coordination of oropharyngeal movements during swallowing (8).

\section{Swallowing maneuvers}

Swallowing maneuvers are designed to bring specific aspects of pharyngeal swallowing under voluntary control. There are four maneuvers:
a) supraglottic swallowing;
b) supersupraglottic swallowing;
c) swallowing with effort;
d) Mendelssohn maneuver.

Supraglottic swallowing involves holding the breath just before the act of swallowing. Supersupraglottic swallowing involves supraglottic swallowing with the chin down. Mendelssohn's maneuver involves digital manipulation of the larynx during swallowing in the upper position for a few seconds (8).

\section{Conclusion}

Based on a critical review of studies on swallowing disorders ranging from 1998 to the present, it can be concluded that many cortical and subcortical structures play a significant role in the act of swallowing and that lesions of these structures affect dysphagia in different ways. The research was mainly based on brain lesions that lead to swallowing disorders after a stroke, and most information is presented in that area. Future studies are needed to expand knowledge and support the development of a neuroanatomical model of swallowing physiology and an approach to adequate and optimal treatment of swallowing disorders. 


\section{References}

1. Leopold N, Kagel M. Pharingo-Esofageal dysphagia in Parkinsons disease. Dysphagia. 1997;7(1):11-18. [CrossRef] [PubMed]

2. Daniels SK. Neurological disorders affecting oral, pharyngeal swallowing. GI Motility. 2006 May; [CrossRef]

3. Jeon W, Park G, Lee J, Joong H. Association between location of brain lesion and clinical factors and findings of videofluoroscopic swallowing study in subacute stroke patients. Brain Neurorehabilitation 2014;7(1): 54-60. [CrossRef]

4. Wilmskoetter J, Bonilha L, Martin-Harris B, Elm JJ, Horn J, Bonilha HS. Mapping acute lesion locations to pshysiological swallow impairments after stroke. Neuroimage Clinical. 2019;22(1):101685.

[CrossRef] [PubMed]

5. Moon HI, Pyun SB, Kwon HK. Correlation between location of brain lesion and cognitive function and findings of videofluoroscopic swallowing study. Ann Rehabil Med. 2012:36(3):347-55. [CrossRef] [PubMed]

6. Daniels SK, Foundas AL. The role of the insular cortex in dysphagia. Dysphagia. 1997;12(3):146-56. [CrossRef] [PubMed]

7. Cola MG, Daniels SK, Corey DM, Lemen LC, Romero $M$, Foundas AL. Relevance of subcortical stroke in dysphagia. Stroke. 2010;41:482-6. [CrossRef] [PubMed]

8. Logemann JA. Evaluation and treatment of swallowing disorders. Austin: Proed;1998. [CrossRef]

9. Suttrup I, Warnecke T. Dysphagia in Parkinsons disease. Dysphagia. 2016;31(1):24-32 [CrossRef] [PubMed]

10. Burgos R, Breton I, Cereda E, Desport JC, Dyiewas R, Genton L, Gomes F, Jesus P, Leischker A, Muscaritoli $M$, Poulia KA, Preiser JC, Wirth R, Singer P, Bischoff SC. ESPEN Guideline clinical nutrition in neurology. Clin Nutr. 2018;37(1):354-96. [CrossRef] [PubMed]

11. Guan XL, Wang H, Huang HS, Meng L. Prevalence od dysphagia in multiple sclerosis: a systematic review and meta-analysis. Neurol Sci. 2015; 36(5): 671-681. [CrossRef] [PubMed]

12. Matsuo K, Palmer JB. Anatomy and Physiology of Feeding and Swallowing - Normal and Abnormal. Phy Med Rehabil Clin N Am. 2008;19(4):691-707. [CrossRef] [PubMed]

13. Martin RE, MacIntosh BJ, Smith RC, Barr AM, Stevens TK, Gati JS, Menon RS. Cerebral areas processing swallowing and tongue movement are overlapping but distinct: a funkcional magnetic resonance imaging study. J Neurophysiol. 2004;92(4):2428-43.

[CrossRef] [PubMed]

14. Jang $\mathrm{S}$, Yang $\mathrm{H}$, Yang $\mathrm{H}$, Kim D. Lesion Characteristics of Chronic Dysphagia in Patients With Supratentorial Stroke. Ann Rehabil Med. 2017;41(2):225-30. [CrossRef] [PubMed]

15. Moon HI, Yoon SY, Yi TI, Jeong YJ, Cho TH. Lesions Responsible for Delayed Oral Transit Time in Poststroke Dysphagia. Dysphagia 2018;33(3):321-8. [CrossRef] [PubMed]

16. Im I, Jun JO, Hwang S, Ko MH. Swallowing outcomes in patients with subcortical stroke associated with lesions of the caudate nucleus and insula. J Int Med Res. 2018;46(9):3552-62. [CrossRef] [PubMed]

17. Martin RE, Goodyear BG, Gati JS, Menon RS. Cerebral cortical representation of automatic and volitional swallowing in humans. J Neurophysiol. 2001;85(2): 928-50. [CrossRef] [PubMed]

18. Daniels SK, Pathak S, Mukhi SV, Stach CB, Morgan $\mathrm{RO}$, Anderson JA. The Relationship Between Lesion Localization and Dysphagia in Acute Stroke. Dysphagia. 2017;32(6):777-84. [CrossRef] [PubMed]

19. Pavlović $D$, Pavlović A. Više kortikalne funkcije neuropsihologije i neurologije ponašanja. Orion art; 2016.

20. Rangarathnam B, Kamarunas E, McCullough GH. Role of Cerebellum in Deglutition and Deglutition Disorders. Cerebellum. 2014;13(6):767-76. [CrossRef] [PubMed]

21. Malandraki G, Sutton B, Perlman A, Karampinos D. Neural activation of swallowing and swallowing-related tasks in healthy young adults. Hum Brain Mapp. 2009; 30(10):3209-26. [CrossRef] [PubMed]

22. Grabski K, Lamalle L, Vilain C, Schwartz JL, Valee N, Tropres I, Baciu M, Le Bas JF, Sato M. Funkctional MRI assessment of orofacial articulators: neural correlates of lip, jaw, larynx, and tongue movements. Hum Brain Mapp. 2012;33(10):2306-21. [CrossRef] [PubMed]

23. Lee SY, Han SH. Relationship Between Subcortical Hemorrhage Size and Characteristics of Dysphagia. Dysphagia. 2019;34(2):155-60. [CrossRef] [PubMed]

24. The American Speech Language Hearing Association. Adult dysphagia:Screening and Assesment. 2009. Available from: URL: https://www.asha.org/PRPSpecificTopic.aspx?folderid $=8589942550 \&$ section $=$ Assessment

25. Daniels SK, Huckabee ML, Gozdzinowska K. Dysphagia following stroke. San Diego: Plural Publishing; 2019. 


\title{
POREMEĆAJI GUTANJA U ODNOSU NA LOKALIZACIJU MOŽDANIH LEZIJA
}

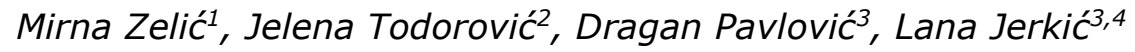

\author{
${ }^{1}$ Zavod za psihofiziološke poremećaje i govornu patologiju „Prof. dr Cvetko Brajović", Beograd, Srbija \\ ${ }^{2}$ Dom zdravlja Zvečan, Zvečan, Srbija \\ ${ }^{3}$ Univerzitet u Beogradu, Fakultet za specijalnu edukaciju i rehabilitaciju, Beograd, Srbija \\ ${ }^{4}$ Stipendista Ministarstva prosvete, nauke i tehnološkog razvoja Republike Srbije \\ Kontakt: Mirna Zelić \\ Kralja Milutina 52, 11000 Beograd, Srbija \\ E-mail: mirnabzelic@gmail.com
}

Poremećaji gutanja (disfagija) obuhvataju kako teškoće u gutanju i kontrolisanju pljuvačke, tako i teškoće prilikom hranjenja. Ove smetnje pogađaju sve starosne grupe, od novorođenčeta do starijih i mogu biti posledica kongenitalnih abnormalnosti, oštećenja anatomskih struktura, koje utiču na gutanje, kao i različitih medicinskih stanja. Disfagija može da bude akutna (npr. izazvana moždanim udarom) ili može da progredira tokom vremena (npr. izazvana tumorima i progresivnim neurološkim bolestima). Brojne regije učestvuju u aktu gutanja i uključuju precentralni girus, postcentralni girus, premotornu zonu, suplementarnu motornu zonu, operculum, insulu, precuneus, prefrontalnu areu, temporalni režanj, mali mozak, moždano stablo, frontalni režanj, capsulu interna, asocijativna polja, talamus i bazalne ganglije. Od izuzetne je važnosti razumevanje procesa gutanja, radi daljeg planiranja adekvatnog pristupa u tretmanu poremećaja ove funkcije.

Acta Medica Medianae 2021;60(1):85-91. disfagije

Ključne reči: disfagija, poremećaji gutanja, patofiziologija gutanja, tretman 